\title{
Are Increasing Urbanisation and Inequalities Symptoms of Growth?
}

\author{
David Castells-Quintana \\ (AQR-IREA - Universidad de Barcelona) \\ dcastells@ub.edu \\ Vicente Royuela \\ (AQR-IREA - Universidad de Barcelona) \\ vroyuela@ub.edu
}

\begin{abstract}
Modern economic growth is apparently characterized by rising income inequalities and increasing urbanisation. By considering both these factors as the two-pronged expression (personal and spatial) of concentration of resources within countries, this paper has focused on how they are associated with the process of economic development. From the perspective of the current policy debate on whether countries should foster increasing spatial concentration even at the risk of higher inequalities, we have briefly revised the main theories interrelating inequality, urbanisation and economic growth. We have analysed the main stylized facts of the association between these variables by using a panel of 51 countries over the period 1970-2007.
\end{abstract}

\section{Keywords:}

Urbanization, urban concentration, inequality, economic growth

JEL classification: $\mathrm{O} 1, \mathrm{O} 4, \mathrm{R} 1$

Acknowledgments We are grateful for comments received at AQR-IREA seminars (Barcelona), at the $9^{\text {th }}$ World Congress of the Regional Science Association International (RSAI) in Timisoara and from two anonymous referees. Both authors acknowledge the financial support of CICYT ECO2010-16006. 


\section{Introduction}

According to World Bank's data, in 1960 almost one third of the World Population lived in cities. In 2010 this figure was above $50 \%$ and was steadily growing by $1 \%$ every three years. At this rate, in 2050 around two thirds of the world population will be living in cities. Cities are the most efficient way for spatially allocating personal, social and economic relationships among individuals. Cities are the place where economic growth happens. As stressed by the World Development Report (WDR) 2009, "economic development is seldom balanced... efforts to spread it prematurely will jeopardize progress" (World Bank 2009, p. 6). Within countries we also see this type of concentration, in so-called "economically leading areas," leading to increasing income disparities across regions, especially in developing countries. Again, according to the WDR 2009, interventions to reduce spatial disparities can be highly inefficient in terms of national growth performance.

Nevertheless, the same WDR points out that "the question is whether growing concentrations of humanity will increase prosperity, or produce congestion and squalor" (World Bank 2009, p. 3). Since 1960, the population in urban agglomerations of more than 1 million inhabitants has accounted for $40 \%$ of total World's urban population, and this figure has remained fairly stable over time (40.8\% in 1960, and 39.2\% in 2010). But urban growth is not only concentrated in large agglomerations. For instance, one of the most distinctive features of urbanisation in Latin America is the rapid growth of small and medium-size cities. Moreover, in many developing countries, rural and urban areas are more and more interconnected, particularly with small and medium-sized centres. In this line, some authors have recently highlighted that economic growth does not need to depend exclusively on increasing urban concentration: "mega-urban regions are not the only possible growth pattern" (Barca et al. 2012, p.141) ... "context and institutions do matter when we consider economic geography” (Barca et al. 2012, p. 144). The OECD (2009a, b, c) also stresses the idea that growth opportunities are both significant in large urban areas and in smaller more peripheral agglomerations. Furthermore, there are advantages for economic development at country level in a "system of cities" of different sizes and specialisations (Duranton and Puga 2004).

The second major trend examined in this paper is the evolution of income inequality over the last four decades. According to Milanovic (2011a), global inequality (considering everybody's actual income) has risen from a Gini index of 0.55 in the 19th century to 0.61 in the first half of the 20th century, and up to 0.65 at the beginning of the 21st century. Milanovic (2012) reported additional information on unweighted international inequality (inequality calculated across unweighted GDPs per capita of all countries in the world) plus weighted international inequality (which uses national GDPs per capita but weights them by populations). He found that since 1952 unweighted international inequality has steadily risen, particularly from the early 1980s. However, according to the same author "after 20 years of mean-income (GDP per capita) divergence, GDPs per capita of the countries of the world have begun a process of convergence since 2001" (Milanovic 2012, p.16), which has been mostly driven by India. Likewise, when considering weighted international inequality we observe a substantial decrease, of 10 Gini points over the last 20 years, which is basically due to China. However, using recent data on household surveys, Milanovic reports an increase in individual global inequality from a Gini index of 68.4 in 1998 to 70.7 in 2005. 
Moreover, while most of global income differences today depend on international location, ${ }^{1}$ the recent increases in global inequality are largely due to increases in inequality within countries.

As we recognise these two global trends, increasing inequality and urbanisation, we revisit here their mutual relationships. The UN Habitat's State of the World's Cities 2008/2009 Report has found that disparities within cities and between cities and regions within the same country are growing. Additionally, the report finds that in cities that have high levels of inequality, economic growth is reduced and that economic growth is often accompanied by rising inequalities. In parallel to city growth, there are growing "informal settlements" or slums as a consequence of increasing rural-urban migration processes. According to UN-Habitat (2009), approximately 1 billion people (1 in every 7 people on the planet) live in urban slums. On the contrary, the International Fund for Agricultural Development (IFAD) 2010 Report highlights that, although still 35\% of the total rural population in developing countries is classified as extremely poor, this figure has come down from around 54\% in 1988.

The main aim of our paper is to analyse the association between economic growth, inequality and urbanisation (and urban concentration). Measures of vertical income inequality capture concentration of resources and wealth among individuals, while measures of urbanisation capture geographical concentration of economic activity. Given that concentration of wealth and resources is subject to positive and negative externalities and synergies, we could expect both income inequality and urban concentration to be associated with benefits from agglomeration of productive resources, which are positive for economic growth, but also to give rise to possibilities of congestion, which are harmful to growth. In effect, as there is a long strand of the literature suggesting theoretical reasons and empirical evidence of positive and negative effects of inequality on economic growth, there is also another strand of the literature suggesting positive and negative effects of urban concentration.

Rather than looking for causality, in this paper we concentrate on describing the different forms of the association between income concentration and economic growth, paying attention to the differences attributable to the level of development of countries. We start by describing the major trends over the period 1970-2007 for a panel of 51 countries, and interpret the main findings in the light of economic theory. For this, we briefly review the theoretical background relating agglomeration, inequality and economic growth (section 2), and next revise what the data say in this regard (section 3). We end by drawing several speculative conclusions in policy terms.

\section{Urbanisation, inequality and economic growth: What does the theory say?}

\subsection{Concentration of resources, good at early stages of development}

The works from Simon Kuznets (1955) and W. Arthur Lewis (1954) postulate that income inequality tends to increase in the early stages of development and then fall once a certain average income is attained, in what is known as the Kuznets inverted-U curve. The models assume perfect labour mobility and a time-constant ratio of the mean incomes between urban and rural areas, while income distribution is presumed to be more uneven in urban than in rural areas. The consequence from these models is economic growth is likely to be associated with increasing urbanisation and income inequality in the short and medium term, but as income increases and a country develops

\footnotetext{
${ }^{1}$ Milanovic (2011b) reported that $51 \%$ of global inequality was due to "class" in the 19 th century, while today this percentage is about $15 \%$, the other $85 \%$ relating to location.
} 
(and becomes more urbanised), inequalities are expected to decrease in the long term. Likewise, Williamson (1965) found that regional inequalities also follow an inverted-U curve according to the general level of country economic development, from the analysis of a panel of 24 countries. Subsequently, Henderson (1974) introduced urbanisation issues in the analysis, showing that the relationship between urban concentration and per capita income also follows an inverted-U pattern.

Thus, inequality and urbanisation, at least in the early stages of development, would be associated with economic growth; they represent capital accumulation and the transformation from a rural to an urban society, in which productivity is much higher. For developing countries the central fact of economic development is rapid capital accumulation (Lewis 1954). And Lewis himself interprets capital accumulation at both the individual and the spatial level. At the individual level that means that the distribution of incomes is altered in favour of the saving class, while at the spatial level that capital and new ideas are not thinly diffused throughout the economy but highly concentrated at a number of points, from which they spread outwards.

In fact, there is empirical evidence for the benefits of concentration of resources. At the individual level, there is evidence of a positive relationship between inequality and growth, at least in the short run: "in the short and medium term, an increase in a country's level of income inequality has a significant positive relationship with subsequent economic growth" (Forbes 2000, p. 869). At the spatial level, we can also find empirical evidence supporting the benefits of urbanisation (Henderson 2003; Brülhart and Sbergami 2009) and urban concentration (Duranton and Puga 2004; Rosenthal and Strange 2004) for growth, especially in developing countries (Bertinelli and Strobl 2007; World Bank 2009). Urbanisation takes place as people and resources are reallocated from agricultural activities to industrial activities -in which value added is higher. Thus, urbanisation represents spatial concentration of production factors necessary for growth, and this concentration itself reinforces labour's reallocation towards larger urban areas (Ross 2000).

\subsection{When concentration of resources goes too far}

The strength of the benefits of agglomeration economies for growth - either from concentration of resources at individual or at geographical level - seems to have a limit. In fact, the relationship between inequality and growth, and between urbanisation and growth, is complex and dependent on several factors.

Previous literature on inequality suggests that its effects on economic growth indeed depend on initial conditions. Some degree of inequality is growth-enhancing at early stages of development but can be growthdeterring at later stages (Galor and Moav 2004). For poor countries, high inequality becomes harmful in the long run (Partridge 1997; Barro 2000). Similarly, increases in inequality harm growth, especially when initial income distribution is already unequal (Chen 2003). In fact, most empirical work on inequality and subsequent long-run growth reports a negative effect (Alesina and Rodrik 1994; Persson and Tabellini 1994; Clarke 1995; Perotti 1996; Easterly 2007; Kanbur and Spence 2010; Castells-Quintana and Royuela 2012). ${ }^{2}$ Additionally, the profile of

\footnotetext{
2 As with the possibility of a positive effect, there are also several channels that would predict a negative effect of inequality on growth: 1) higher inequality implies higher socio-political instability and the risk of violent conflict, which translates into uncertainty in property rights, reducing investment and growth (Alesina and Perotti 1996). 2) Inequality generates a redistributive pressure, potentially leading to economic distortions and disincentives that harm growth (Alesina and Rodrik 1994; Persson and Tabellini 1994). 3) In the presence of credit-market imperfections, higher inequality reduces the capacity of
} 
inequality itself matters; inequality at the top of the distribution has a positive effect on growth, while inequality at the bottom has a negative one (Voitchovsky 2005).

Regarding urbanisation measures, the literature suggests that the effects of urbanisation on growth depend on income level (Henderson 2003; Brülhart and Sbergami 2009). ${ }^{3}$ In fact, it has been suggested that while geographical concentration of economic activity is likely to enhance growth in early stages of development, it can slow it down in later stages due to congestion diseconomies - the so-called Williamson hypothesis (Williamson 1965). Brülhart and Sbergami find a critical level of per capita GDP of US $\$ 10.000$ (in 2006 prices) above which higher urbanisation becomes detrimental to growth. In addition, we expect that the effects of urban concentration on economic growth also depend on initial levels of concentration, both in terms of urbanisation (as in Bertinelli and Back 2004) and of income distribution (Castells-Quintana and Royuela 2014).

\subsection{Increasing inequality and increasing urban concentration}

Recent projections on how cities will look like in 2050 argue that a systematic strategic approach has to be considered, in which several interconnected pillars (cornerstones) should address policy response. According to Nijkamp and Kourtit (2012, p. 3), "a question of critical importance is how urban regions around the world can play a central role in creating wealth, enhancing social development, attracting investments, and harnessing both human and technological resources in productivity and competitiveness at local and global scales". One of these connections between pillars is between social capital and social participation, innovation and economic vitality. In that way, inequality and economic forces driving urban growth, and vice versa.

The relationship between development and income inequality described by the classical models of development is highly related to urbanisation processes. In fact, the effect of inequality on economic growth described in Partridge (1997) and Barro (2000) is about development, and it can be measured both in income terms and of course in urbanisation terms. Two reasons to explain the inverted-U relationship between urbanisation and inequality can be given. On one hand, the mean income differential between the agricultural sector and the urban sector, and the progressive migration from the first to the second, is sufficient to give the inverted-U relationship (Robinson 1976; Knight 1976; Fields 1979). On the other hand, this relationship can also be explained by income differentials within the urban sector, where a higher variance is expected. In later stages of development, inequality falls back as urbanisation increases: the exodus from agriculture raises rural wages and lowers willingness to migrate at risk of urban underemployment (Rauch, 1993). But if conditions are dramatically different between the urban and rural areas, incentives to migrate are going to be very high. In fact, dramatic differences between conditions in rural

many to invest and increases macroeconomic volatility (Aghion et al., 1999), which reduce average investment, especially in human capital (Galor and Zeira 1993), lowering long-run growth. 4) High inequality also implies a higher share of population with low purchasing power, which, given that the poor tend to demand local products, reduces aggregate demand (Todaro 1997). 5) Finally, higher inequality is also related to higher fertility rates, which in turn reduces growth; in particular, as the number of children per family increases, the average investment in education decreases (Barro 2000; Ehrhart 2009).

${ }^{3}$ As Brülhart and Sbergami note, different spatial scales imply different mechanisms at work and, therefore, may yield different results. At small spatial scales, there are positive spillovers associated with clustering activities (mainly knowledge spillovers) and agglomeration may have a positive impact on economic growth even, and probably more importantly, in more developed countries. Their results, however, refer to the larger spatial scale that is associated with urbanization, at which the agglomeration impact relates to a reduction of transaction costs and higher integration of markets. 
areas and expected income in urban areas help to explain the rapid rise of urban slums that is characteristic of the developing world (high levels of urban concentration and of both urban-rural inequality and intra-urban inequality). In any case, urban slums are also related to a lack of response from the supply side and not an inevitable consequence of urbanisation.

Briefly, the capacities that countries have to benefit from agglomeration economies due to concentration of resources both at the individual as at the spatial level and to avoid the risks of congestion vary significantly from country to country. As we have already mentioned, the process of urbanisation and urban concentration can be driven by different forces (Kim 2008) and evolve in different ways; Bloom et al. (2008) compare industrialisationdriven urbanisation with urbanisation due to population pressure and conflict, with dramatically different results. There are substantial differences in urbanisation patterns that need to be better understood as "urban dynamics are not just a social science problem; they are where economic development processes hit the ground and generate many challenges for public and private actors and individuals" (Storper et al. 2012, p.4). Likewise, higher inequality can be the result of market dynamics, being associated with growth, or it can be the result of socio-institutional factors that are most probably harmful to growth (Easterly 2007). In this sense, identifying the nature of the processes involved in the concentration of resources (i.e. in inequality and urban concentration) and underlying forces in each country, becomes of major relevance to policy design. In this line, institutional arrangements emerge as a key factor.

Thus, if urbanisation and agglomeration are seen as a positive process for development, at the same time "where institutions are insufficiently developed, it may well be the case that urban expansion is the only realistic option for overcoming institutional problems and promoting growth and development" (Barca et al. 2012, p. 141). Consequently, urbanisation can be the result not only of agglomeration forces (i.e. forces pulling towards cities), but also as a consequence of a lack of a proper institutional environment in a country, where the displacement of people and resources from rural to urban areas can be driven by "pathological non-economic factors", such as war, ethnic conflict and bright lights, rather than by agglomeration economies and higher productivity (Kim 2008). Furthermore, it is expected that the process of urban concentration will lead, sooner or later and especially when institutional conditions are not appropriate, to congestion diseconomies. What becomes evident is the need of a more segregated analysis of the relationship between inequality, urban concentration and economic growth, differentiating among countries at different stages of development.

\section{What are data telling us?}

\subsection{Describing the database}

The development of wider and more precise databases allows researchers to test their theoretical positions against the reality. Several approaches can be considered in this regard. For our analysis, we used panel data on inequality, urbanisation, urban concentration and economic growth, all at country level. For inequality we used Gruen and Klasen's (2008) coefficients, which are from the WIID-WIDER database, adjusted for the different possible objects 
of measurement, and related to household or family and for the entire population. ${ }^{4}$ For economic growth we considered the cumulative annual average per capita GDP growth rate, constructed with data from Summers and Heston's database, using real GDP chain data. For urbanisation measures we used data from the World Bank (World Development Indicators): initial rate of urbanisation (URB), initial rate of population in agglomerations of more than 1 million as percentage of the total population (URB_1M) - which captures urban concentration - and the difference between these two variables, which we have labelled as the percentage of the population living in small and medium-size cities (URB_SMC). Data availability on inequality constrained our sample to 51 countries having data for the period 1970-2007. We included data for 1970, 1980, 1990 and 2000 and growth in each subsequent decade in the panel. The sample included 11 countries from Latin-America \& the Caribbean, 2 from North-America, 10 from Africa, 13 from Asia, 1 from Oceania and 14 from Europe. ${ }^{5}$

We examined both the long-run evolution and the levels of urbanisation, urban concentration and inequality. For simplicity and clarity, here the focus of the data exploration has been descriptive, analysing parallel trends during the process of economic development and no attempt has been made at establishing causal links. ${ }^{6}$

\subsection{Long-term associations}

Our first set of descriptive statistics considers the association between the levels of inequality, urbanisation and economic development (i.e. income levels) across countries. One of the assumptions considered when building such comparisons is that countries are similar to each other. The only factor setting them apart is timing of industrialisation, which helps to explain the delay in the process of structural transformation from a rural to an urban society (Gollin et al. 2002)..$^{7}$ Consequently, we assumed that the association between the variables was longstanding, since doubling real GDP of a nation usually takes decades.

Inequality and development. Figures 1a and 1b display scatterplots of real GDP and the Gini Index in 1970 and 2000, respectively. A non-linear relationship that can be likened to the Kuznets curve was observed for 1970. It is reasonable to assume that poorer countries will increase their inequality as they develop, but that this inequality will subsequently decrease.

\footnotetext{
4 The main and most complete dataset on Gini coefficients is the World Income Inequality Database (WIID-WIDER). In addition to quality, there are three other important items in the construction of Gini coefficients that should be considered when using these coefficients to study interactions between inequality and economic growth: 1) the object of measure - gross income, net income, expenditure or consumption-, 2) the unit of measure -individual, family or household-, and 3) the coverage of data -urban, rural or all. According to Knowles (2001), it is best to use net income, expenditure or consumption, as the explanations of the effects of inequality on growth relate to income distribution after redistribution has taken place. Data on Gini coefficients based on expenditure or consumption are scarce, particularly in developing countries. Therefore, data based on net (or disposable) income, measuring household or family income and total population coverage should be preferred.

${ }^{5}$ The dataset is available upon request. The full list of countries includes: Australia, Bangladesh, Belgium, Bolivia, Brazil, Canada, China, Colombia, Costa Rica, Cote d'Ivoire, Denmark, Ecuador, Egypt, El Salvador, Finland, France, Greece, Honduras, Hong Kong, Hungary, India, Indonesia, Ireland, Italy, Jamaica, Korea, Republic of Madagascar, Malawi, Malaysia, Mexico, Morocco, Nepal, Netherlands, Nigeria, Norway, Pakistan, Panama, Peru, Philippines, Portugal, South Africa, Spain, Sri Lanka, Sweden, Tanzania, Thailand, Tunisia, Turkey, United Kingdom, United States and Zambia.

${ }^{6}$ In line with other researches conducted in several development studies, such a Myrskylä et al (2009), where cross-sectional and between-country trajectories using a longitudinal perspective are considered.

${ }^{7}$ Several papers in the literature assume that recent industrialisation processes have faster transformations than what the United States or the United Kingdom accomplished (see Duarte and Restuccia 2007, for the case of Portugal).
} 
Figure 1: Association between Real GDP per capita and Inequality

a. 1970

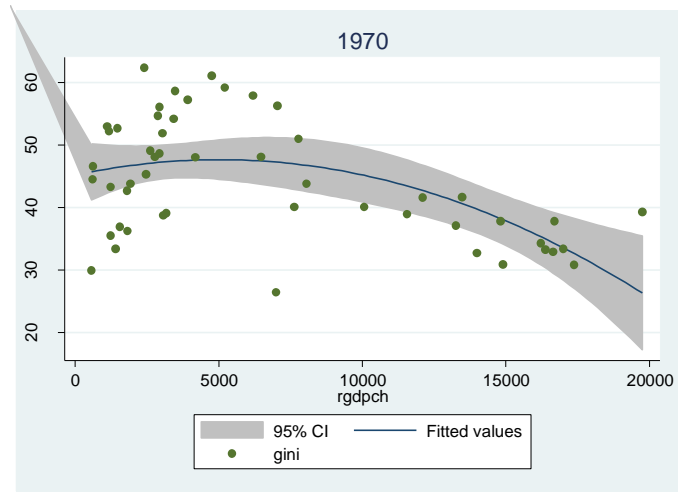

b. 2000

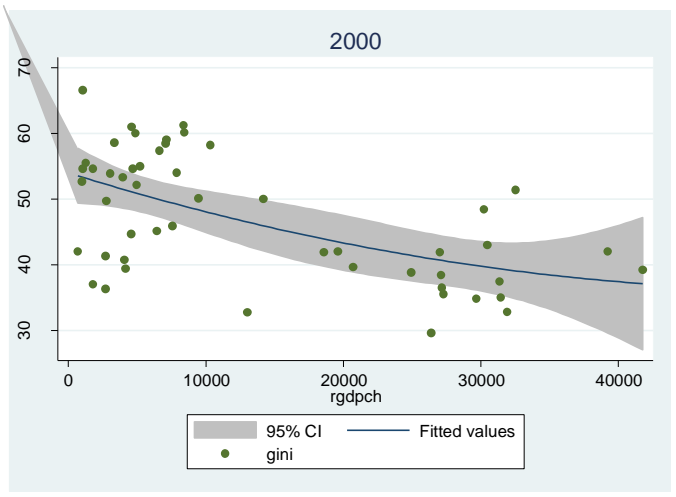

Urbanisation and development. Figs. 2a to $2 \mathrm{f}$ show again that, as countries develop, they experience an increase in the urbanisation rate at a diminishing return. This is expected because urbanisation rate is a truncated variable. When looking at the relationship between economic development and urban concentration in cities of more than 1 million, and in small- and medium-sized cities (cities between the urbanisation threshold and 1 million), we observed that most developed and developing countries had similar proportions of the population living in cities of more than one million inhabitants, while developed countries displayed a larger proportion of people living in small- and medium-sized cities.

Inequality and urbanisation (Figs. 3a-3f). While there was no relationship at the international level in large cities, urbanisation in small- and medium-sized cities was negatively related both with the level and the variance of the Gini index, i.e. countries with a large proportion of people living in small- and medium-sized cities had lower inequalities than countries with a large proportion of their population living in big cities. 
Figure 2: Association between Real GDP per capita and Urbanisation

a. 1970. Urbanisation rate

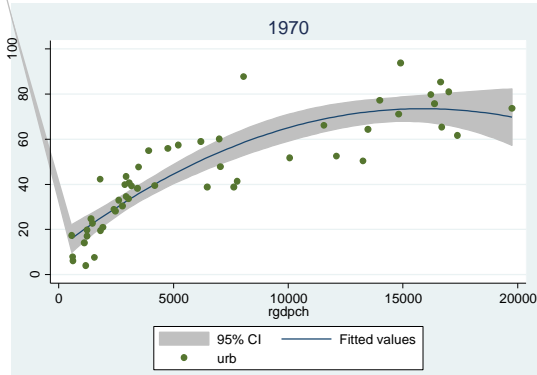

d. 2000. Urbanisation rate

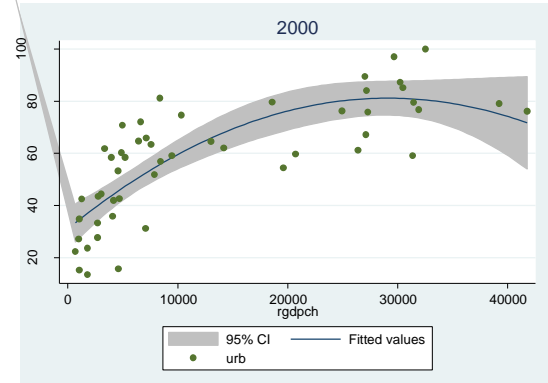

e. 2000. Urbanisation 1 Million

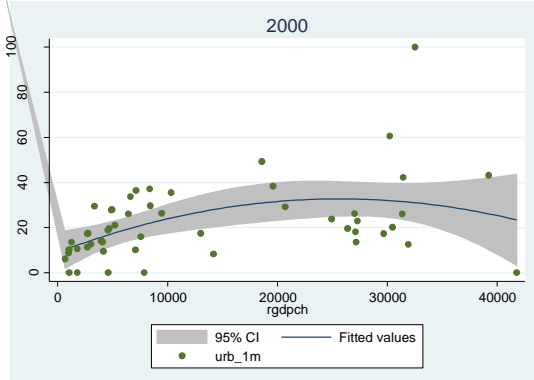

c. 1970. Urb. Small- \& Medium-sized
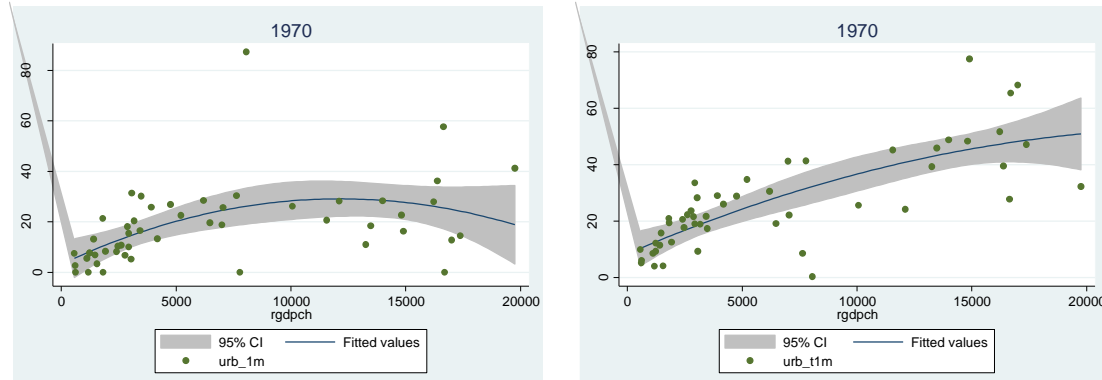

f. 2000. Urb. Small- \& Medium-sized

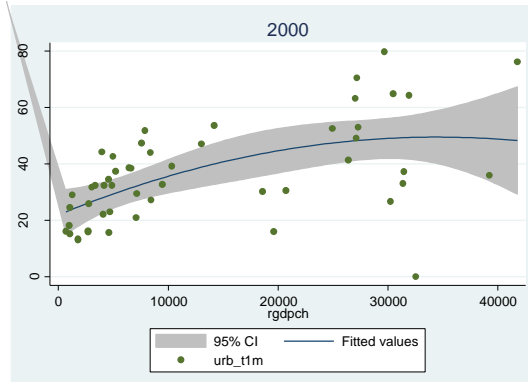

Figure 3: Association between Inequality and Urbanisation

a. 1970. Urbanisation rate

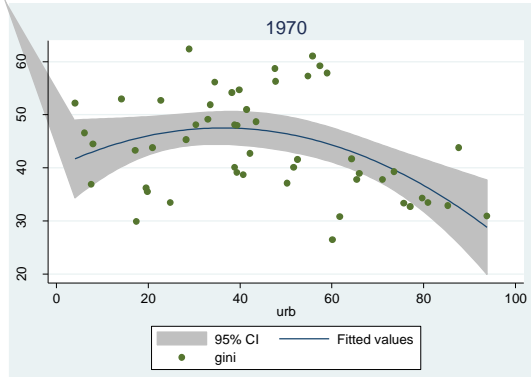

d. 2000. Urbanisation rate

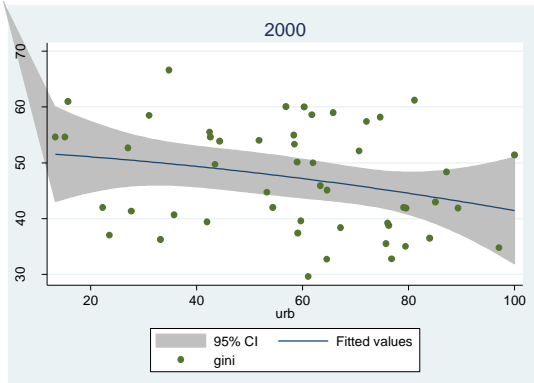

b. 1970. Urbanisation 1 Million
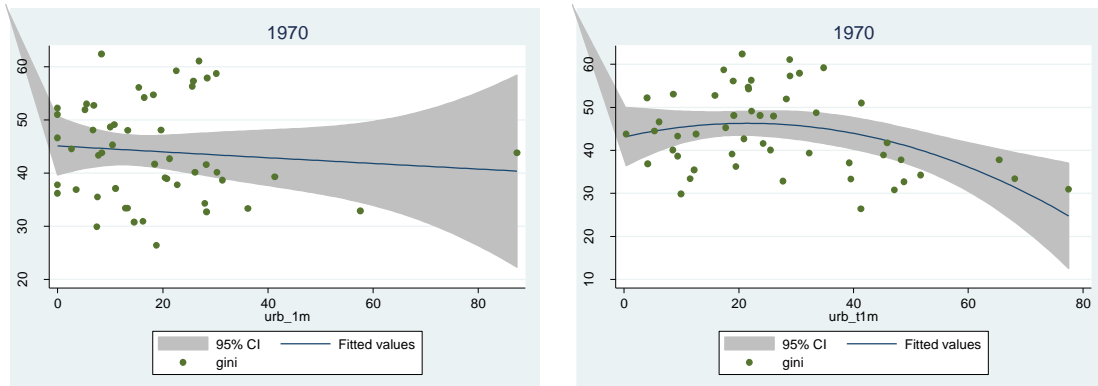

e. 2000. Urbanisation 1 Million

f. 2000. Urb. Small- \& Medium-sized
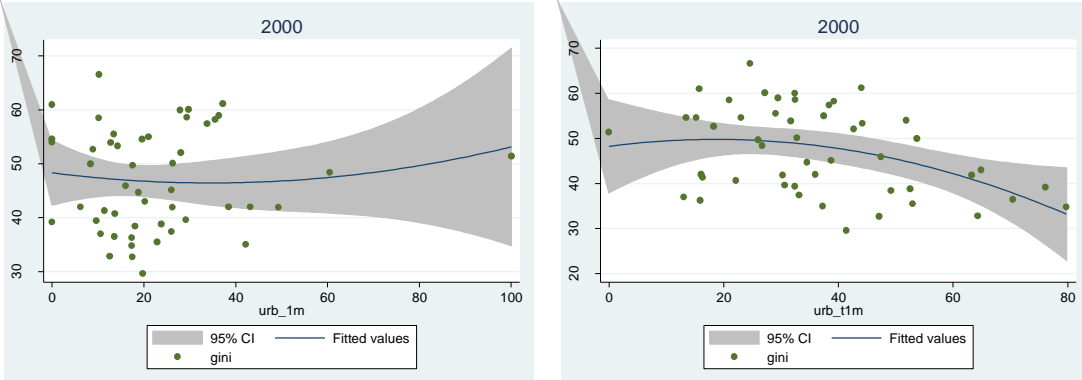
Table 1: Correlation coefficients

\begin{tabular}{|c|c|c|c|c|c|c|c|c|c|c|c|c|c|c|c|c|c|c|c|c|c|c|c|c|c|}
\hline & \multicolumn{5}{|c|}{ ALL COUNTRIES } & \multicolumn{5}{|c|}{$\begin{array}{l}\text { MORE DEVELOPED } \\
\text { COUNTRIES } \\
\text { (GDP above the median) }\end{array}$} & \multicolumn{5}{|c|}{$\begin{array}{l}\text { LESS DEVELOPED } \\
\text { COUNTRIES } \\
\text { (GDP below the median) }\end{array}$} & \multicolumn{5}{|c|}{$\begin{array}{l}\text { MORE EQUAL COUNTRIES } \\
\text { (Gini below the median) }\end{array}$} & \multicolumn{5}{|c|}{$\begin{array}{c}\text { MORE UNEQUAL COUNTRIES } \\
\text { (Gini above the median) }\end{array}$} \\
\hline & $\begin{array}{l}\text { gdp } \\
\text { growth }\end{array}$ & rgdpch & gini & urb & $\begin{array}{l}\text { urb } \\
1 \mathrm{~m}\end{array}$ & $\underset{\text { growth }}{\text { gdp }}$ & rgdpch & gini & urb & $\begin{array}{l}\text { urb } \\
1 \mathrm{~m}\end{array}$ & $\begin{array}{l}\text { gdp } \\
\text { growth }\end{array}$ & rgdpch & gini & urb & $\begin{array}{l}\text { urb } \\
1 \mathrm{~m}\end{array}$ & $\begin{array}{l}\text { gdp } \\
\text { growth }\end{array}$ & rgdpch & gini & urb & $\begin{array}{l}\text { urb } \\
1 \mathrm{~m}\end{array}$ & $\begin{array}{l}\text { gdp } \\
\text { growth }\end{array}$ & rgdpch & gini & urb & $\begin{array}{l}\text { urb } \\
1 \mathrm{~m}\end{array}$ \\
\hline & \multicolumn{5}{|c|}{1970} & \multicolumn{5}{|c|}{1970} & \multicolumn{5}{|c|}{1970} & \multicolumn{5}{|c|}{1970} & \multicolumn{5}{|c|}{\begin{tabular}{|r|}
1970 \\
\end{tabular}} \\
\hline $\begin{array}{l}\text { rgdpch } \\
\text { gini } \\
\text { urb } \\
\text { urb } 1 \mathrm{~m} \\
\text { urb t1m } \\
\end{array}$ & $\begin{array}{c}0,00 \\
-0,06 \\
0,18 \\
\mathbf{0 , 3 3} \\
-0,06 \\
\end{array}$ & $\begin{array}{c}-0,49 \\
0,85 \\
0,41 \\
0,77 \\
\end{array}$ & $\begin{array}{l}-\mathbf{0 , 3 0} \\
-0,09 \\
\mathbf{- 0 , 3 2} \\
\end{array}$ & $\begin{array}{l}0,67 \\
0,75\end{array}$ & 0,00 & $\begin{array}{c}-0,11 \\
0,01 \\
0,22 \\
\mathbf{0 , 5 0} \\
-0,29 \\
\end{array}$ & $\begin{array}{c}\mathbf{- 0 , 7 4} \\
\mathbf{0 , 6 4} \\
0,01 \\
\mathbf{0 , 5 7} \\
\end{array}$ & $\begin{array}{l}-\mathbf{0 , 5 2} \\
-0,01 \\
-0,46 \\
\end{array}$ & $\begin{array}{l}0,45 \\
0,46 \\
\end{array}$ & $-0,59$ & $\begin{array}{c}0,21 \\
-0,11 \\
0,31 \\
0,32 \\
0,15 \\
\end{array}$ & $\begin{array}{l}0,44 \\
0,86 \\
0,65 \\
0,72 \\
\end{array}$ & $\begin{array}{l}0,29 \\
0,11 \\
0,36 \\
\end{array}$ & $\begin{array}{l}0,81 \\
0,77 \\
\end{array}$ & 0,25 & $\begin{array}{c}-0,15 \\
0,05 \\
-0,02 \\
0,10 \\
-0,09 \\
\end{array}$ & $\begin{array}{c}-0,08 \\
\mathbf{0 , 8 9} \\
\mathbf{0 , 4 2} \\
\mathbf{0 , 7 7} \\
\end{array}$ & $\begin{array}{r}-0,18 \\
0,10 \\
-0,27 \\
\end{array}$ & $\begin{array}{l}0,52 \\
0,83\end{array}$ & $-0,04$ & $\begin{array}{c}0,07 \\
0,00 \\
0,31 \\
\mathbf{0 , 4 2} \\
-0,14 \\
\end{array}$ & $\begin{array}{l}0,21 \\
\mathbf{0 , 8 3} \\
\mathbf{0 , 6 3} \\
\mathbf{0 , 4 6} \\
\end{array}$ & $\begin{array}{l}0,32 \\
0,07 \\
\mathbf{0 , 4 7} \\
\end{array}$ & $\begin{array}{l}0,84 \\
0,42 \\
\end{array}$ & $-0,13$ \\
\hline urb t1m & \multicolumn{5}{|c|}{1980} & \multicolumn{5}{|c|}{1980} & \multicolumn{5}{|c|}{1980} & \multicolumn{5}{|c|}{1980} & \multicolumn{5}{|c|}{1980} \\
\hline $\begin{array}{l}\text { rgdpch } \\
\text { gini } \\
\text { urb } \\
\text { urb } 1 \mathrm{~m} \\
\text { urb t1m }\end{array}$ & $\begin{array}{c}0,10 \\
\mathbf{- 0 , 5 3} \\
0,03 \\
0,14 \\
-0,09\end{array}$ & $\begin{array}{c}-0,51 \\
0,84 \\
0,41 \\
0,70 \\
\end{array}$ & $\begin{array}{r}-\mathbf{0 , 3 4} \\
-0,09 \\
\mathbf{- 0 , 3 6} \\
\end{array}$ & $\begin{array}{l}0,62 \\
0,72\end{array}$ & $-0,11$ & $\begin{array}{c}\mathbf{0 , 4 7} \\
\mathbf{- 0 , 5 2} \\
0,32 \\
0,18 \\
0,09 \\
\end{array}$ & $\begin{array}{r}\mathbf{- 0 , 6 1} \\
\mathbf{0 , 6 6} \\
0,09 \\
\mathbf{0 , 4 5} \\
\end{array}$ & $\begin{array}{c}-0,48 \\
0,07 \\
-0,46\end{array}$ & $\begin{array}{l}0,37 \\
\mathbf{0 , 4 6}\end{array}$ & $-0,65$ & $\begin{array}{c}0,06 \\
\mathbf{- 0 , 6 9} \\
0,00 \\
0,25 \\
-0,30\end{array}$ & $\begin{array}{l}0,22 \\
\mathbf{0 , 8 9} \\
\mathbf{0 , 8 0} \\
\mathbf{0 , 6 6}\end{array}$ & $\begin{array}{l}0,28 \\
0,05 \\
\mathbf{0 , 4 6}\end{array}$ & $\begin{array}{l}0,86 \\
0,79 \\
\end{array}$ & 0,37 & $\begin{array}{c}\mathbf{- 0 , 5 0} \\
0,20 \\
-0,24 \\
0,27 \\
-\mathbf{0 , 4 7} \\
\end{array}$ & $\begin{array}{r}-0,07 \\
\mathbf{0 , 8 5} \\
0,25 \\
\mathbf{0 , 7 4} \\
\end{array}$ & $\begin{array}{r}-0,15 \\
0,26 \\
-0,36\end{array}$ & $\begin{array}{l}0,48 \\
0,72\end{array}$ & $-0,26$ & $\begin{array}{c}0,04 \\
-0,39 \\
-0,13 \\
-0,15 \\
-0,03\end{array}$ & $\begin{array}{r}-0,28 \\
\mathbf{0 , 8 3} \\
\mathbf{0 , 8 4} \\
0,35 \\
\end{array}$ & $\begin{array}{l}-0,15 \\
-0,14 \\
-0,09\end{array}$ & $\begin{array}{l}0,86 \\
0,67\end{array}$ & 0,19 \\
\hline urb t1m & \multicolumn{5}{|c|}{1990} & \multicolumn{5}{|c|}{1990} & \multicolumn{5}{|c|}{1990} & \multicolumn{5}{|c|}{1990} & \multicolumn{5}{|c|}{1990} \\
\hline $\begin{array}{l}\text { rgdpch } \\
\text { gini } \\
\text { urb } \\
\text { urb } 1 \mathrm{~m} \\
\text { urb t1m } \\
\end{array}$ & $\begin{array}{c}0,21 \\
\mathbf{- 0 , 4 2} \\
0,08 \\
0,09 \\
0,02 \\
\end{array}$ & $\begin{array}{c}-0,58 \\
0,79 \\
0,42 \\
0,59 \\
\end{array}$ & $\begin{array}{l}-\mathbf{0 , 3 2} \\
-0,01 \\
\mathbf{- 0 , 3 9} \\
\end{array}$ & $\begin{array}{l}0,63 \\
0,66 \\
\end{array}$ & $-0,17$ & $\begin{array}{c}0,12 \\
-0,22 \\
-0,09 \\
0,06 \\
-0,14 \\
\end{array}$ & $\begin{array}{c}\mathbf{- 0 , 7 0} \\
\mathbf{0 , 5 9} \\
0,12 \\
0,32 \\
\end{array}$ & $\begin{array}{r}\mathbf{- 0 , 4 1} \\
0,16 \\
-\mathbf{0 , 4 8} \\
\end{array}$ & $\begin{array}{l}\mathbf{0 , 4 3} \\
0,29 \\
\end{array}$ & $-0,73$ & $\begin{array}{c}0,18 \\
\mathbf{- 0 , 5 1} \\
-0,09 \\
-0,07 \\
-0,10 \\
\end{array}$ & $\begin{array}{l}0,02 \\
\mathbf{0 , 7 2} \\
\mathbf{0 , 6 7} \\
\mathbf{0 , 6 1} \\
\end{array}$ & $\begin{array}{l}0,25 \\
0,22 \\
0,23 \\
\end{array}$ & $\begin{array}{l}0,87 \\
0,89 \\
\end{array}$ & 0,56 & $\begin{array}{c}-0,17 \\
0,18 \\
-0,15 \\
0,04 \\
-0,21 \\
\end{array}$ & $\begin{array}{c}-0,28 \\
\mathbf{0 , 8 9} \\
\mathbf{0 , 4 0} \\
\mathbf{0 , 7 8} \\
\end{array}$ & $\begin{array}{r}-0,39 \\
0,16 \\
\mathbf{- 0 , 5 8} \\
\end{array}$ & $\begin{array}{l}0,56 \\
0,81 \\
\end{array}$ & $-0,04$ & $\begin{array}{c}0,38 \\
\mathbf{- 0 , 4 4} \\
0,22 \\
0,18 \\
0,05 \\
\end{array}$ & $\begin{array}{c}-\mathbf{0 , 4 1} \\
\mathbf{0 , 7 0} \\
\mathbf{0 , 8 5} \\
-0,27 \\
\end{array}$ & $\begin{array}{r}-0,22 \\
-0,22 \\
0,00 \\
\end{array}$ & $\begin{array}{l}\mathbf{0 , 8 0} \\
0,28 \\
\end{array}$ & $-0,35$ \\
\hline & \multicolumn{5}{|c|}{2000} & \multicolumn{5}{|c|}{2000} & \multicolumn{5}{|c|}{2000} & \multicolumn{5}{|c|}{2000} & \multicolumn{5}{|c|}{2000} \\
\hline $\begin{array}{l}\text { rgdpch } \\
\text { gini } \\
\text { urb } \\
\text { urb } 1 \mathrm{~m} \\
\text { urb } 1 \mathrm{~m}\end{array}$ & $\begin{array}{c}-0,22 \\
0,08 \\
-0,22 \\
-0,06 \\
-0,23\end{array}$ & $\begin{array}{c}-0,57 \\
0,74 \\
0,40 \\
0,54\end{array}$ & $\begin{array}{c}-0,27 \\
0,03 \\
-\mathbf{0 , 3 6}\end{array}$ & $\begin{array}{l}0,63 \\
0,64\end{array}$ & $-0,19$ & $\begin{array}{c}-0,16 \\
-0,03 \\
-0,04 \\
0,22 \\
-0,27\end{array}$ & $\begin{array}{c}\mathbf{- 0 , 5 9} \\
\mathbf{0 , 5 3} \\
0,16 \\
0,20\end{array}$ & $\begin{array}{l}-0,09 \\
0,27 \\
-0,36\end{array}$ & $\begin{array}{l}\mathbf{0 , 4 6} \\
0,21\end{array}$ & $-0,77$ & $\begin{array}{l}-0,11 \\
-0,03 \\
-0,12 \\
-0,12 \\
-0,10\end{array}$ & $\begin{array}{l}0,19 \\
\mathbf{0 , 6 5} \\
\mathbf{0 , 6 4} \\
\mathbf{0 , 5 5}\end{array}$ & $\begin{array}{l}0,20 \\
0,15 \\
0,22\end{array}$ & $\begin{array}{l}0,92 \\
0,91\end{array}$ & 0,68 & $\begin{array}{c}\mathbf{- 0 , 5 5} \\
0,09 \\
-\mathbf{0 , 5 5} \\
-0,25 \\
-\mathbf{0 , 4 4}\end{array}$ & $\begin{array}{c}-0,28 \\
\mathbf{0 , 8 2} \\
0,29 \\
\mathbf{0 , 7 1}\end{array}$ & $\begin{array}{c}-0,15 \\
0,18 \\
-0,26\end{array}$ & $\begin{array}{l}0,39 \\
0,84\end{array}$ & $-0,18$ & $\begin{array}{c}0,01 \\
0,33 \\
-0,01 \\
0,03 \\
-0,06\end{array}$ & $\begin{array}{c}-0,36 \\
\mathbf{0 , 7 0} \\
\mathbf{0 , 8 1} \\
-0,14\end{array}$ & $\begin{array}{l}-0,22 \\
-0,13 \\
-0,15\end{array}$ & $\begin{array}{l}\mathbf{0 , 8 3} \\
0,35\end{array}$ & $-0,24$ \\
\hline
\end{tabular}


Table 1 displays the correlation coefficients between the considered variables for each and all available years for the 51 countries considered (see section 3.1). In order to find out if there were non-linearities, we divided the sample into two different subsets: higher and lower GDP per capita levels, and higher and lower inequality levels. ${ }^{8}$ Together with the levels of urbanisation, inequality and development, we added the measure of economic growth during the subsequent decade. From these data we note the following stylised facts:

- Higher levels of development - in terms of real GDP per capita - were associated with lower levels of inequality and higher levels of urbanisation. However over the years the relationship was stronger for inequality and weaker for urbanisation. Nevertheless, in less-developed countries, both higher inequality and higher urbanisation were positively associated with the process of development.

- The sign of the association between inequality and urbanisation also depended on the stage of development: higher urbanisation rates (particularly in small- and medium-sized cities) were negatively associated with inequality in more developed countries, while they were positively associated in the less developed ones.

- While in developed countries urban concentration in large cities (more than one million inhabitants) was negatively associated with urbanisation in small and medium-sized cities, the association was positive in the less developed countries.

- We only saw a significant negative correlation between economic growth and the initial level of GDP in the subsample of more equal countries (unconditional economic convergence). Economic growth was usually negatively correlated with initial inequality and positively with initial urban concentration, although only in the 1970s.

Overall, we found non-linearities between all three variables (inequality, urbanisation and economic development), as suggested by our literature review. On the one hand, non-linearities between inequality and development were in line with the Kuznets inverted-U hypothesis (see, also, Partridge 1997, and Barro 2000). On the other hand, non-linearities were identified between urbanisation and development, in line with the Williamson hypothesis (similarly to Henderson 2003, and Brülhart and Sbergami 2009). However, our analysis also revealed non-linearities in the relationship between urbanisation and inequality; the correlation between inequality and urbanisation was positive for less-developed countries but negative for more developed ones.

\subsection{Dynamic association}

An alternative and complementary approach is to inspect the relationships between the evolutions rather than the levels themselves of the considered variables. Our dataset allowed analysing these evolutions over a relatively long period (1970-2000). Figure 4 shows the association between economic growth and the increase in inequalities in the 51 countries considered, Figures $5 \mathrm{a}$ to $5 \mathrm{c}$ display the scatterplots of real GDP per capita growth against the growth of the three considered types of urbanisation, and finally Figures $6 \mathrm{a}$ to $6 \mathrm{c}$ show growth of the Gini index versus the growth of urbanisation. Similarly, tables 2 and 3 display the correlation coefficients between growth rates of the

${ }^{8}$ We divided the full sample using every period median of every variable. 
considered variables, also including the interaction between urbanisation and Gini growth rates to have a closer look at potential non-linearities, and acknowledging our intuition of both processes representing concentration of resources.

Figure 4: Economic growth and Inequality growth. 1970-2000.

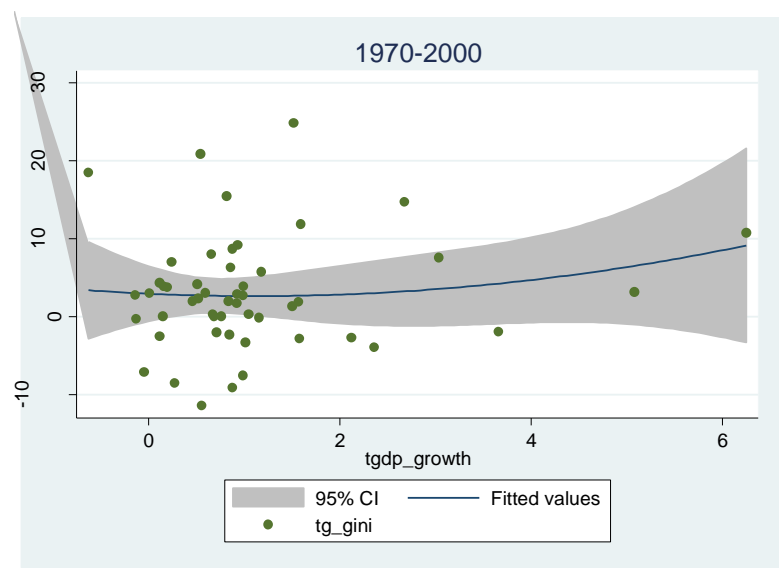

Figure 5: Economic growth and Urbanisation growth. 1970-2000.

a. Urbanisation rate

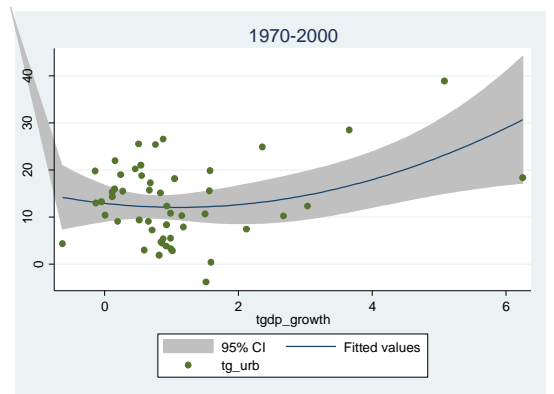

b. Urbanisation 1 Million

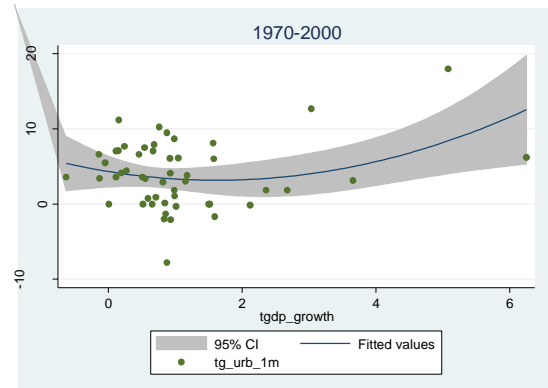

c. Urb. Small \& Medium-sized

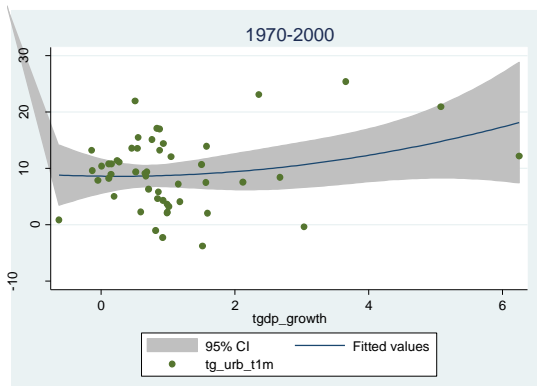

Figure 6: Inequality growth and Urbanisation growth. 1970-2000.

\section{a. Urbanisation rate}

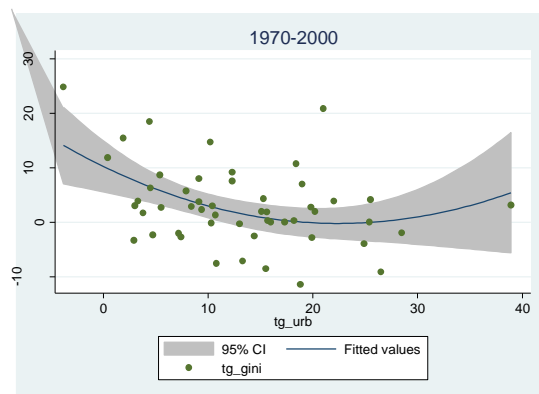

b. Urbanisation 1 Million

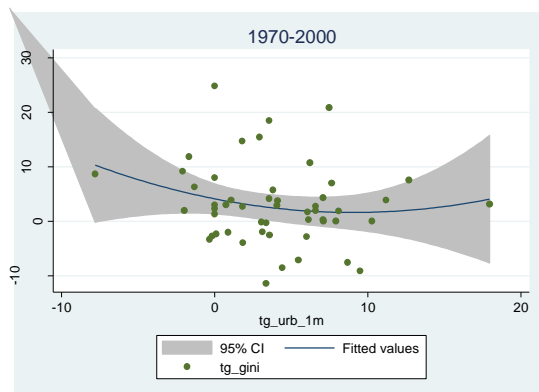

c. Urb. Small \& Medium-sized

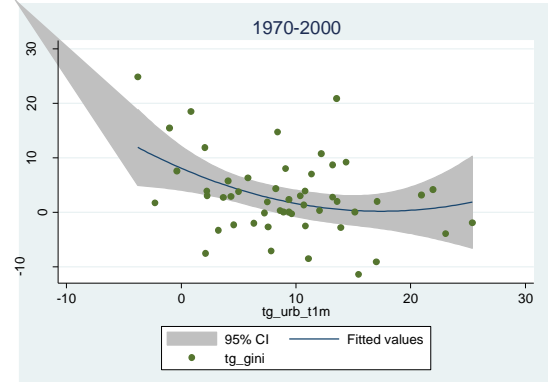


Table 2: Correlation between growth rates (1970-2000): Full sample (51 countries)

\begin{tabular}{|l|cccc|}
\cline { 2 - 5 } \multicolumn{1}{c|}{} & $\begin{array}{c}\text { gdp } \\
\text { growth }\end{array}$ & $\begin{array}{c}\text { Urb } \\
\text { growth }\end{array}$ & $\begin{array}{c}\text { Urb 1M } \\
\text { growth }\end{array}$ & $\begin{array}{c}\text { Urb SMC } \\
\text { growth }\end{array}$ \\
\hline Urb growth & $\mathbf{0 . 2 9}$ & & & \\
Urb 1M growth & 0.21 & $\mathbf{0 . 6 5}$ & & \\
Urb SMC growth & 0.23 & $\mathbf{0 . 8 5}$ & 0.15 & \\
Gini Growth & 0.12 & $\mathbf{- 0 . 3 4}$ & -0.16 & $\mathbf{- 0 . 3 3}$ \\
Gini g* Urb g & 0.18 & 0.07 & 0.12 & 0.01 \\
Gini g* Urb1M g & 0.22 & 0.12 & $\mathbf{0 . 3 7}$ & -0.11 \\
Gini g* Urb SMC g & 0.12 & 0.03 & -0.04 & 0.07 \\
\hline
\end{tabular}

Note: bolded correlations were significant at the $5 \%$ level and coefficients in italics were significant at $10 \%$.

Table 3: Correlation between growth rates (1970-2000): Subsamples

\begin{tabular}{|cccc|cccc|}
\hline $\begin{array}{c}\text { gdp } \\
\text { growth }\end{array}$ & $\begin{array}{c}\text { Urb } \\
\text { growth }\end{array}$ & $\begin{array}{c}\text { Urb 1M } \\
\text { growth }\end{array}$ & $\begin{array}{c}\text { Urb SMC } \\
\text { growth }\end{array}$ & $\begin{array}{c}\text { gdp } \\
\text { growth }\end{array}$ & $\begin{array}{c}\text { Urb } \\
\text { growth }\end{array}$ & $\begin{array}{c}\text { Urb 1M } \\
\text { growth }\end{array}$ & Urb SMC growth \\
\hline
\end{tabular}

\begin{tabular}{|c|c|c|c|c|c|c|c|c|}
\hline \multirow[b]{2}{*}{ Urb growth } & \multicolumn{3}{|c|}{ (GDP above the median) } & TRIES & & $\begin{array}{l}\text { DEVE } \\
\text { (GDP }\end{array}$ & $\begin{array}{l}\text { PED C } \\
\text { w the } n\end{array}$ & RIES \\
\hline & 0.65 & & & & 0.01 & & & \\
\hline Urb 1M growth & 0.54 & 0.64 & & & -0.15 & 0.67 & & \\
\hline Urb SMC growth & 0.43 & 0.80 & 0.06 & & 0.09 & 0.92 & 0.31 & \\
\hline Gini Growth & -0.06 & -0.20 & -0.16 & -0.13 & 0.23 & -0.53 & -0.26 & -0.54 \\
\hline Gini $g *$ Urb $g$ & 0.23 & 0.18 & 0.16 & 0.11 & 0.19 & 0.03 & 0.14 & -0.04 \\
\hline Gini $g *$ Urb1M g & 0.43 & 0.20 & 0.57 & -0.18 & 0.14 & 0.02 & 0.20 & -0.09 \\
\hline Gini $g *$ Urb SMC $g$ & -0.07 & 0.05 & -0.26 & 0.27 & 0.20 & 0.04 & 0.11 & -0.01 \\
\hline
\end{tabular}

\begin{tabular}{|l|cccc|ccc|c|}
\cline { 2 - 8 } \multicolumn{1}{c|}{} & \multicolumn{3}{c}{$\begin{array}{c}\text { MORE EQUAL COUNTRIES } \\
\text { (Gini below the median) }\end{array}$} & \multicolumn{3}{c|}{$\begin{array}{c}\text { MORE UNEQUAL COUNTRIES } \\
\text { (Gini above the median) }\end{array}$} \\
\hline Urb growth & $\mathbf{0 . 5 4}$ & & & 0.06 & & \\
Urb 1M growth & $\mathbf{0 . 4 4}$ & $\mathbf{0 . 6 8}$ & & -0.02 & $\mathbf{0 . 5 9}$ & \\
Urb SMC growth & 0.38 & $\mathbf{0 . 8 2}$ & 0.14 & & 0.08 & $\mathbf{0 . 8 9}$ & 0.16 & $-\mathbf{- 0 . 5 4}$ \\
Gini Growth & 0.34 & -0.22 & -0.25 & -0.10 & 0.11 & $\mathbf{- 0 . 5 6}$ & -0.26 & 0.09 \\
Gini g * Urb g & $\mathbf{0 . 5 2}$ & -0.11 & -0.05 & -0.11 & -0.07 & 0.18 & 0.22 & -0.15 \\
Gini g * Urb1M g & $\mathbf{0 . 6 1}$ & 0.09 & 0.29 & -0.09 & 0.02 & 0.06 & $\mathbf{0 . 4 1}$ & 0.22 \\
Gini g * Urb SMC g & 0.38 & -0.19 & -0.20 & -0.10 & -0.11 & 0.22 & 0.09 & \\
\hline
\end{tabular}

Note: bolded correlations were significant at the $5 \%$ level and coefficients in italics were significant at $10 \%$.

From figures 4 to 6 and the correlation in tables 2 and 3, the following can be pointed out:

- The increase in urbanisation in all samples was more correlated with the increase in urbanisation in small and medium-sized cities than with the increase in large cities.

- Economic growth was apparently associated with urban growth, but only in the more developed and in the more equal countries.

- Economic growth was apparently associated with growth in inequality, but only when the initial distribution of income was more equal (correlation significant at the $10 \%$ level). 
- Increasing urbanisation was associated with decreasing inequality. This was apparently true in all the subsamples considered and for all types of urbanisation rate, but was only strongly significant for the growth of small and medium-sized cities in the less-developed and in the more unequal countries.

Finally, from the literature review in section 2 we have seen that the sign of the association between the considered variables depended on both the initial level of inequality and on the level of economic development. In a closer analysis, we divided our sample of 51 countries into four subsamples depending on level of economic development and inequality, i.e. high-high, high-low, low-high and low-low, respectively. By taking advantage of the panel structure of our database, we expanded the database serially by considering growth rates in 10-year intervals: 1970-80, 1980-90, 1990-2000. Table 4 shows the correlations for every subsample, where every observation is of a country and period of time.

We found a positive association between growth in urbanisation rates and economic growth, which again was dependent on the level of economic development. The association was only strong for the less-developed countries with a more equal distribution of income, and was especially associated with urban concentration in large cities. Likewise, we found a positive association between growth and urbanisation rate and inequality only for these less developed and more equal countries (see bottom right panel in table 4). Both factors relate to the fact that the interaction between growth and urbanisation rates and inequality was the variable with the highest correlation with economic growth in these countries. In other words: in less developed countries and with better income distribution there were increases in urbanisation and inequality that were associated with growth, in line with the first development phase of the Kuznets' and Lewis' models. In these countries, urban growth is highly associated with both large cities and small and medium-sized cities. By contrast, for more developed countries or for countries with an unequal distribution of income, we do not see any significant positive correlation between growth in urbanisation or in inequality and economic growth. If any, the correlation with urban concentration is negative, although nonsignificant in our sample. Consequently, additional increases in the concentration of resources are apparently not associated with better economic outcomes in these countries. 
Table 4: Correlation between growth rates (1970-80; 1980-90; 1990-2000): Subsamples

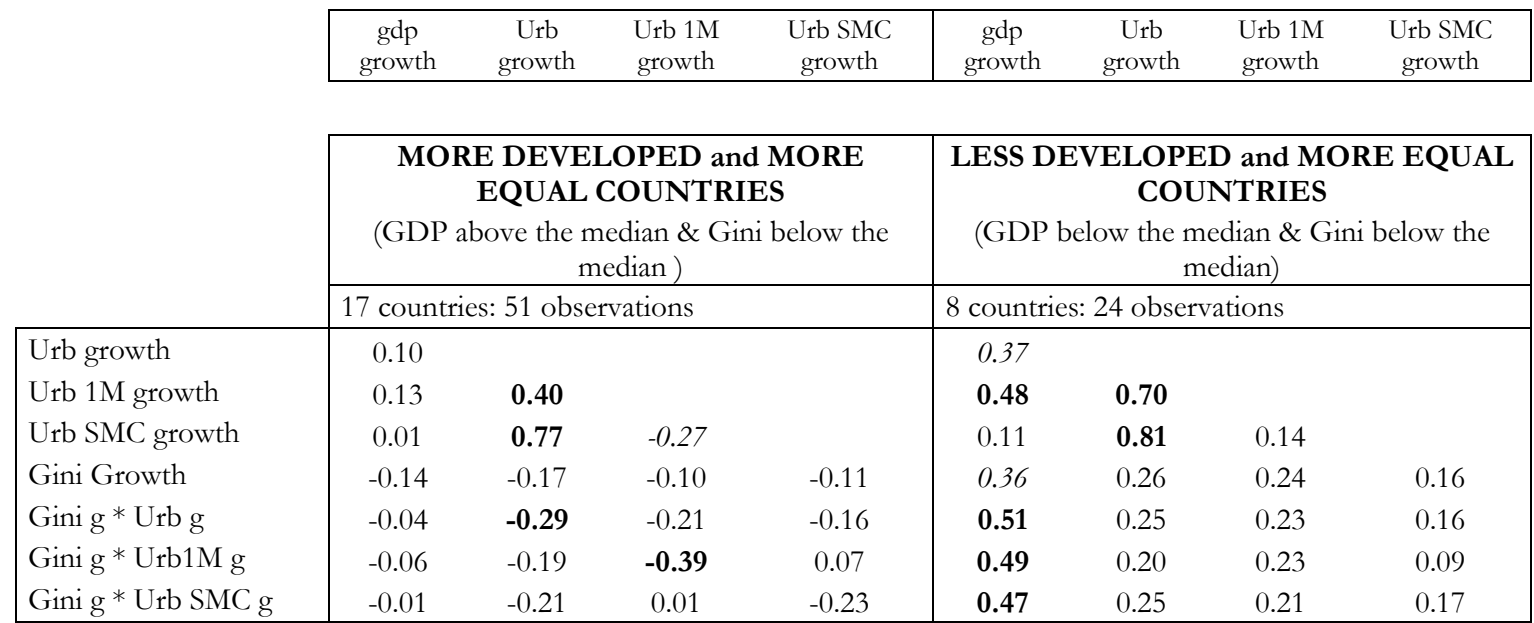

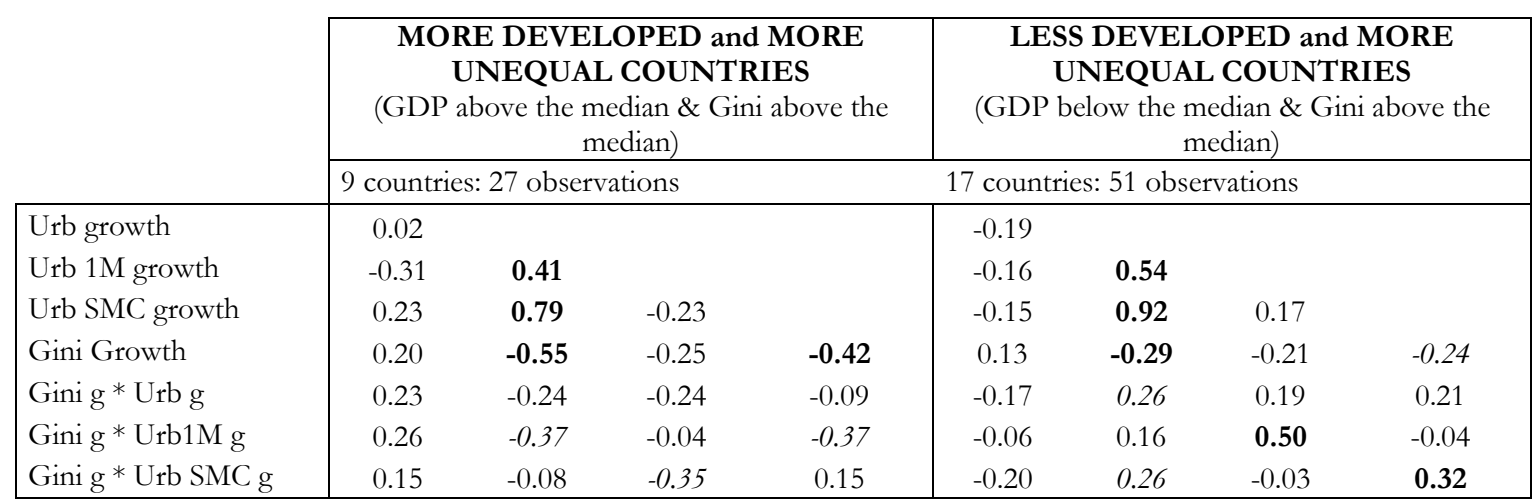

Note: correlations in bold are significant at the $5 \%$ level and correlations in italics are significant at $10 \%$.

\section{Discussion and conclusions}

The main goal addressed in this paper was to describe the main stylised facts in the association between concentration of resources and economic development. We have considered both the personal dimension (inequality) and the spatial dimension (urbanisation) of concentration of resources and, after briefly revising the main theories relating to these issues, we analysed the main stylised facts by using a panel of 51 countries over the period 19702007. In sum, and in line with the literature, we identified that spatial and individual concentration of resources may indeed be associated with the process of development, especially during the early stages. Three non-linearities arise: 1) Kuznets inverted-U between development and inequality; 2) Williamson-Henderson inverted-U between spatial concentration and development; and 3) a non-linear relationship between inequality and urbanisation that is dependent on the level of development, i.e. if a country is initially rural and income is equally distributed, increasing urbanisation and inequality go hand in hand and are associated with economic growth while, by contrast, in countries with unequal distribution of income, this association is not found. 
While we understand that the increasing inequalities and urbanisation of the last decades have been associated with growth in countries during their early stages of development, our analysis also suggests that as countries develop, the beneficial forces behind the concentration of resources are likely to become exhausted. In fact, the interactions between increasing urbanisation, increasing inequality and economic growth change as countries circumstances also change. As we have seen here, the benefits associated with agglomeration depend on existing levels of concentration of resources. A further contribution of our work has been the analysis of the urbanisation rates in small and medium-sized cities. In already developed or unequal countries, i.e. countries in which concentration of resources is already high, urbanisation in small and medium-sized cities appears to be associated with decreasing inequality. Small and medium-sized cities emerge as an alternative for growth opposed to urban congestion in larger cities. Indeed, a negative correlation exists between these two types of urbanisation in these countries, and increasing urbanisation in large cities is expected to lead to increasing inequalities (Behrens and Robert-Nocoud 2009).

Overall, we contend that the current policy debate on whether countries should foster increasing urban concentration, even at the risk of higher inequalities, has to be contextualized. In particular, acknowledging the powerful forces of agglomeration economies while also acknowledging the fact that socio-economic and institutional factors and circumstances, like inequalities, are relevant factors in themselves and as shifters on how agglomeration forces play a role on economic growth. Two interesting lines for further research arise. On the one hand, a more formal analytical research is clearly needed in order to find not only associations between urbanisation, inequality and economic growth but also to extract causal relationships between these variables. On the other hand, we need a better understanding of the dynamics behind urbanisation, urban concentration, and inequality.

\section{Acknowledgments}

We are grateful for comments received at AQR-IREA seminars (Barcelona), at the $9^{\text {th }}$ World Congress of the Regional Science Association International (RSAI) in Timisoara and from two anonymous referees. Both authors acknowledge the financial support of CICYT ECO2010-16006.

\section{References}

Aghion, P., Caroli, E., \& Garcia-Peñalosa, C. (1999). Inequality and economic growth: the perspective of the new growth theories. Journal of Economic Literature, 37(4), 1615-1660.

Alesina, A. and Rodrik, D. (1994). Distributive politics and economic growth. The Quarterly Journal of Economics, 109, 465-490.

Alesina, A. and Perotti, R. (1996). Income distribution, political instability, and investment. European Economic Review, 40, 12031228.

Barca, F., McCann, P., \& Rodríguez-Pose, A. (2012). The case for regional development intervention: Place-based versus placeneutral approaches. Journal of Regional Science 52(1), 134-152.

Barro, R. J. (2000). Inequality and growth in a panel of countries, Journal of Economic Growth, 5, 5-32.

Bertinelli, L., and Black, D. (2004). Urbanization and growth. Journal of Urban Economics, 56, 80-96.

Bertinelli, L., \& Strobl, E. (2007). Urbanisation, Urban Concentration and Economic Development. Urban Studies, 44(13), 24992510 .

Behrens, K. and Robert-Nicoud, F. (2009). Survival of the fittest in cities: Agglomeration, polarization, and inequality. CIRPÉE Discussion Paper \#09-19. 
Bloom, D. E., Canning, D., and Fink, G. (2008). Urbanization and the wealth of nations. Science (New York, N.Y.), 319(5864), 772-5.

Brülhart, M., \& Sbergami, F. (2009). Agglomeration and growth: Cross-country evidence. Journal of Urban Economics, 65(1), 4863. Elsevier Inc.

Castells-Quintana, D. and Royuela, V. (2012). Unemployment and long-run economic growth: The role of income inequality and urbanisation. Investigaciones Regionales, 24, 153-173.

Castells-Quintana, D. and Royuela, V. (2014). Agglomeration, inequality and economic growth. Annals of Regional Science, 52(2), 343-266.

Chen, B. (2003). An inverted-U relationship between inequality and long-run growth. Economic Letters, 78, $205-212$.

Clarke, G. (1995). More evidence on income distribution and growth, Journal of Development Economics, 47, 403-427.

Duranton, G. and D. Puga. (2004) Micro-Foundations of Urban Agglomeration Economies. Handbook of Urban and Regional Economics, Vol. 14, Geography and Cities. J.V. Henderson and J-F Thisse eds.

Easterly, W. (2007). Inequality does cause underdevelopment: Insights from a new instrument. Journal of Development Economics, 84(2), 755-776.

Ehrhart, C. (2009). The effects of inequality on growth: a survey of the theoretical and empirical literature, ECINEQ, 2009-107.

Fields, G.S. (1979). A Welfare Economic Approach to Growth and Distribution in the Dual Economy, Quarterly Journal of Economics, 93(3), 325-353.

Forbes, K. (2000). A reassessment of the relationship between inequality and growth, The American Economic Review. 90(4), 86987.

Galor, O. and Moav, O. (2004). From Physical to Human Capital Accumulation: Inequality and the Process of Development. Review of Economic Studies, 71(4), 1001-1026.

Galor, O and Zeira, J. (1993) Income Distribution and Macroeconomics. The Review of Economic Studies, 60(1), 35-52.

Gollin, D., Parente, S.L., and Rofgerson, R. (2002). The role of agriculture in development. American Economic Review, 92, 160164.

Gruen, C. and Klasen, S. (2008). Growth, inequality, and welfare: comparisons across time and space, Oxford Economic Papers, 60, 212-236.

Henderson, V. (1974). Optimum City Size: The External Diseconomy Question, Journal of political Economy, col. 82(2), 373-88.

Henderson, V. (2003). The Urbanization Process and Economic Growth: The So-What Question, Journal of Economic Growth, 8 , 47-71.

International Fund for Agricultural Development. (2010). IFAD's 2010 Rural Poverty Report.

Kanbur, R. and Spence, M. (2010). Equity and Growth in a Globalized World. Washington D.C.: Commission on Growth and Development /World Bank.

Kim, S. (2008). Spatial Inequality and Economic Development: Theories, Facts and Policies. Working Paper nr. 16, Commission on Growth and Development.

Knight, J.B. (1976). Explaining Income Distribution in Less Developed Countries: A Framework and an Agenda, Oxford Bulletin of Economics and Statistics, 38(3), 161-177.

Knowles, S. (2001). Inequality and economic growth: The empirical relationship reconsidered in the light of comparable data, Centre for Research in Economic Development and International Trade, 1/03.

Kuznets, S. (1955). Economic Growth and Income Inequality. American Economic Review, 45 (March), 1-28.

Lewis, W. A. (1954), Economic Development with Unlimited Supplies of Labour. The Manchester School, 22, 139-191.

Milanovic, B. (2011a). Global Income Inequality by the Numbers: in History and Now - An Overview. World Bank Policy Research Working Paper No. 6259.

Milanovic, B. (2011b). Global Inequality: From Class to Location, from proletarians to Migrants. World Bank Policy Research Working Paper No. 5820.

Milanovic, B. (2012). Global inequality recalculated and updated: the effect of new PPP estimates on global inequality and 2005 estimates. Journal of Economic Inequality, 10, 1-18.

Nijkamp, P., Kourtit, K. (2012): “The new urban Europe”: Global Challenges and Local Responses in the Urban Century. European Planning Studies, 21(3), 291-315.

OECD (2009a). How Regions Grow, Paris. Organisation for Economic Cooperation and Development.

OECD (2009b). Regions Matter: Economic Recovery, Innovation and Sustainable Development. Paris. Organisation for Economic Cooperation and Development.

OECD (2009c). Regions at a Glance. Paris. Organisation for Economic Cooperation and Development.

Partridge, M. (1997). Is inequality harmful for growth? A note. American Economic Review, 87(5), 1019-1032.

Perotti, R. (1996). Growth, income distribution and democracy: what the data say? Journal of Economic Growth 1, $149-187$.

Persson , T. and G. Tabellini. (1994). Is Inequality Harmful for Growth? Theory and evidence. American Economic Review, 84, 600-21.

Rauch, J. E. (1993). Economic Development, Urban underemployment, and Income Inequality, Canadian Journal of Economics, $26,901-18$ 
Robinson, S. (1976). A Note on the U- Hypothesis Relating Income Inequality and Economic Development, American Economic Review, 66(3), 437-440.

Ross, J. (2000). Development theory and the economics of growth, The University of Michigan Press. MI.

Rosenthal, S. and Strange, W. (2004) Evidence on the Nature and Sources of Agglomeration Economies. Handbook of Urban and Regional Economics, Vol. 14, Geography and Cities J.V. Henderson and J-F Thisse eds. (2004)

Storper, M. Van Marrewijk, C. and Van Oort, F. (2012). Introduction: Process of Change in Urban Systems. Journal of Regional Science, vol. 53 (1), 1-9.

Todaro, M. (1997). Economic Development. (6th edition). New York: Longman.

UN-HABITAT. (2009). United Nations Habitat's State of the World's Cities 2008/09 Report. UN-Habitat Press.

Voitchovsky, S. (2005). Does the profile of income inequality matter for economic growth? Distinguishing Between the Effects of Inequality in Different Parts of the Income Distribution. Journal of Economic Growth, 10(3), 273-296.

Williamson, J. (1965). Regional inequality and the process on national development. Economic Development and Cultural Change, 4 , 3-47.

World Bank. (2009). World Development Report 2009: Reshaping economic geography. Washington D.C: World Bank. 